\title{
Features from a Single Vector Pressure Stroke
}

\author{
Qiang Li, ${ }^{1}$ Changhai Yang, ${ }^{1}$ Zhao Zhang, ${ }^{1}$ Xi Wang, ${ }^{2}$ Yongjian Gong, ${ }^{3}$ and Cuixian Xuan \\ ${ }^{1}$ State Key Laboratory of Automobile Simulation and Control, Jilin University, Changchun, Jilin, China \\ ${ }^{2}$ FAW-Volkswagen Automotive Co., Ltd., Changchun, Jilin, China \\ ${ }^{3}$ Jinhua Polytechnic, Jinhua, Zhejiang, China \\ Correspondence should be addressed to Changhai Yang; ych@jlu.edu.cn
}

Received 19 May 2016; Revised 22 August 2016; Accepted 15 September 2016; Published 3 January 2017

Academic Editor: Chaudry M. Khalique

Copyright (C) 2017 Qiang Li et al. This is an open access article distributed under the Creative Commons Attribution License, which permits unrestricted use, distribution, and reproduction in any medium, provided the original work is properly cited.

\begin{abstract}
Freehand sketching in a real-time 3D styling system presents a different way to create a 3D model from the traditional CAD system. Strokes are the most common and useful objects in the expression of a stylist's intention by using the gesture commands and in the construction of geometries. Not only are they sketched freely as drawing on a paper with a pen, but also they can be converted automatically into spline curves and then can be used to form a surface. Therefore, it is necessary to investigate the features of stroke, the extraction and identification of these features, and the applications. Here, the features from a single vector pressure stroke have been discussed in detail according to their applications in an automotive freehand styling system in the early stage of conceptual design. The features have been divided into three parts: the input features, the calculable feature, and the added features. Over a hundred features have been defined and classified with the geometry or performance attributes. The features proposed have been applied in the identification of gesture commands, the expression of art vector stroke by pseudoantialiasing method, and a novel method to generate a spatial curve directly by the pressure of stroke in AutoSketch system.
\end{abstract}

\section{Introduction}

Strokes are not only used in the generation of geometries but also applied in many related manipulations to assist sketching, which make the freehand sketching system more natural and suitable for creative design. The most direct application is that the strokes are converted into images in a raster graphics system, for example, in Painter or Photoshop, or transformed into curves in a vector graphic system, for example, TEDDY [1], I Love Sketch system [2], or AutoSketch [3] (Figure 1), which is quite different from the curve generations in the traditional CAD systems. A multistroke combination method has been proposed by Li et al. [4-6]. In recent years, more features have been applied into AutoSketch system for the requirement of real-time $3 \mathrm{D}$ sketching $[7,8]$, especially the pressure information of digital pen that has been used to creature the spatial curve and express the style of stroke, in which more features from the strokes are calculated [9]. Strokes can be drawn like art sketching on a paper with a pencil or marker pen.
For the sketched strokes, one issue is to determine the geometries, for example, the curves from the strokes such as straight lines, arcs, or parabolic curves, and the geometry shapes such as triangles, rectangles, and circles [10-13]. Most of them are regular or standardized geometries and there are many methods to identify them, in which the segmentations are quite common methods to find the primitives from the strokes using features such as geometrical or velocity features $[14,15]$. Another issue is to determine the meanings of gesture command sketched. Many gesture command strokes go with the sketching system. Some gesture strokes are designed for specific manipulations in I Love Sketch system (Figure 2). A scratch-out stroke means to delete an object, a roll stroke stands for an undo manipulation, and a small lasso stroke is to select a curve or set a subcoordinate system. The gesture command strokes in AutoSketch support manipulations such as select, undo, redo, and delete (Figure 3). Similar gesture strokes have also been presented in Feng et al's gesture-based handwriting mathematics editing system [16] (left) and Song's ISID [17] (right) systems (Figure 4). 


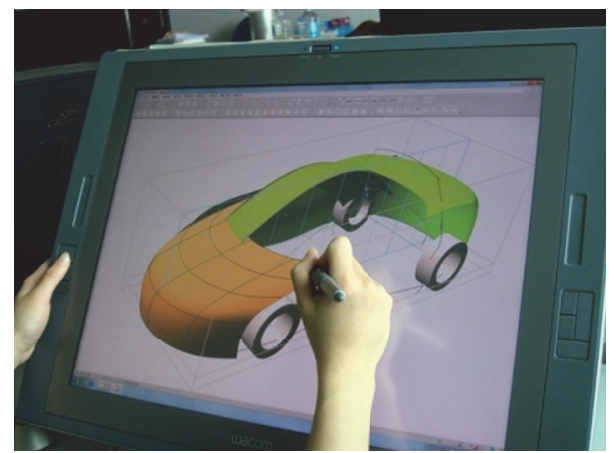

FIGURE 1: Sketching in AutoSketch system.

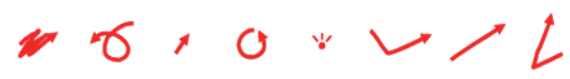
(a) Scratch out
(e) Period
(b) Roll
f) Span
(c) Tick
(g) Flick
(d) Small lasso
(h) Angled flick

FIGURE 2: Gesture strokes in I Love Sketch system.

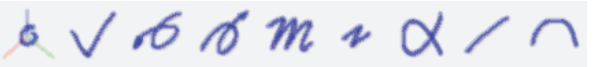

FIgURE 3: Gesture strokes in AutoSketch system.

Almost all the definitions of gesture command stroke depend on the techniques of identification [18]. The methods can be summarized into three aspects: the template matching techniques, the statistical analysis techniques, and the neural network techniques. However, it is necessary to dig out the implicit features from a single vector pressure stroke, which may be applied in many applications. Here, only the vector stroke has been discussed because the raster stroke is not easily obtained in a vector CAD system and is bad in realtime performance [19].

A single vector pressure stroke is obtained easily in a vector graphic system with a sequence array, which consists of a series of points. The data is smaller than that of raster stroke relatively, which has a good real-time performance [20].

The features discussed here have been investigated and implemented into AutoSketch system for the identification of standardized geometries and gesture commands. There are five parts of related research works for the development of AutoSketch system: the combination of multistrokes, the identification of sketched gesture commands, the standardization of freehand sketched geometries, the transformation of curves or surfaces from $2 \mathrm{D}$ to $3 \mathrm{D}$, and the application of pressure information. This work related four projects: a novel algorithm from 2D sketch to 3D surface model in automotive styling (Science Fund Project of State Key Laboratory of Advanced Design and Manufacturing for Vehicle Body (SKLVBDM2006001)), study on the key technology of integration of 2D hand sketching and 3D automotive styling (State "863" Project (2008AA04Z110)), research on

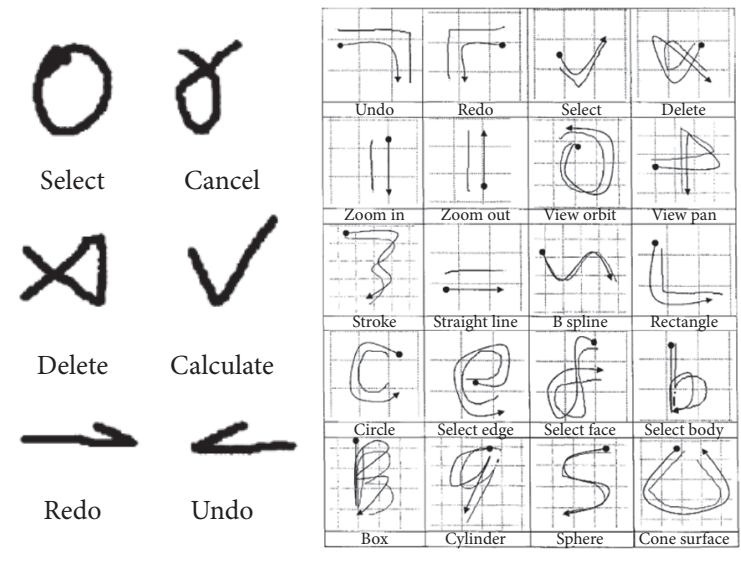

FIGURE 4: Gesture strokes in Feng's system and ISID.

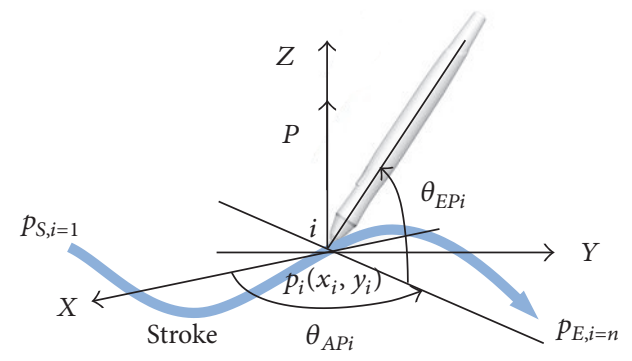

FIGURE 5: Input features.

TABLE 1: Input features and formulae.

\begin{tabular}{lclc}
\hline Number & Feature & Definition & Formula and value \\
\hline 1 & $i$ & Serial number of point & $i \in[1, n]$ \\
2 & $n$ & Number of points & $n \geq 1$ \\
3 & $p_{i}\left(x_{i}, y_{i}\right)$ & Coordinates on the screen & $p_{i} \in[(0,0),(w, h)]$ \\
4 & $P_{i}$ & Pressure of pen & $P_{i} \in[0,255]$ \\
5 & $\theta_{A P i}$ & Azimuth angle of pen & $\theta_{A P} \in[0,360]$ \\
6 & $\theta_{E P i}$ & Elevation angle of pen & $\theta_{E P} \in\left[0,90^{\circ}\right]$ \\
\hline
\end{tabular}

input method of 3D freehand sketching in automotive styling (Science and Technology Plan Projects of Jinhua City (20111-045)), and 3D automotive freehand styling system based on the pressure of digital pen and the combination of strokes (Science and Technology Plan Projects of Zhejiang Province (2013C31085)).

These features can be classified into three parts: input, calculable, and added ones.

\section{Input Features}

The input features are obtained from the output of a digital pen (Figure 5). They are put into an array with the data format of $\left(x_{i}, y_{i}, P_{i}, \theta_{A P i}, \theta_{E P i}\right)$, and its size is $n$ (Table 1 and Figure 1). Each point of a stroke contains the information of coordinates, pressure, azimuth angle, and elevation angle. The values of coordinates are within the screen of computer in pixel, where the width is $w$ and the height is $h$. 
TABLE 2: Calculation features.

\begin{tabular}{|c|c|c|c|}
\hline Number & Feature & Definition & Formula and value \\
\hline 1 & $a_{\min }$ & $\begin{array}{l}\text { Min. } \\
\text { value of } \\
\text { parameter } \\
a\end{array}$ & $a_{\min }=\min \left\{a_{i}\right\}$ \\
\hline 2 & $a_{\max }$ & $\begin{array}{l}\text { Max. } \\
\text { value of } \\
\text { parameter } \\
a\end{array}$ & $a_{\max }=\max \left\{a_{i}\right\} \quad a \in\{x, y, v\}$ \\
\hline
\end{tabular}

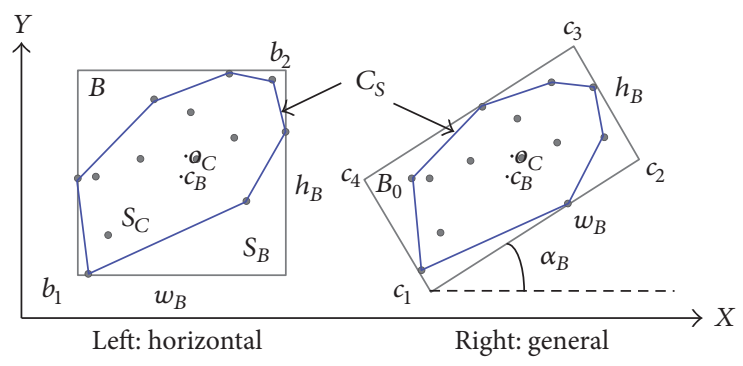

FIgure 6: Box containers.

There are only the first four input features that have been used in AutoSketch system until now. The azimuth and elevation angles will be applied to investigate the characteristics of the stylist's sketching in the future researches. Therefore, the following discussions are not related to the angles.

\section{Calculable Features}

Calculable features are those that can be calculated out directly from the input ones. There may be different calculable features according to the real applications. Generally, these features are, according to our researches, classified into six parts: extreme value, coordinate, length and width, angle, performance, and auxiliary features.

3.1. Extreme Value Features. There are two extreme value features, $a_{\min }$ and $a_{\max }$ (Table 2). The functions of min. and max. are used for finding the minimum and maximum values from a set of parameters, respectively. The parameter $a$ will be replaced by the parameter $x, y$, or $v$ as needed. The extreme values are used for the determination of the container of an object.

3.2. Coordinate Features. A series of points contains the coordinates in $X-Y$ plane. Some special coordinates are listed in Table 3.

A container is a minimum rectangle or box including an object. $B\left\{b_{1}, b_{2}\right\}$ stands for a simple horizontal container (Figure 6, left), which is represented by two diagonal points; another is a more general one $B_{0}\left\{c_{1}, c_{2}, c_{3}, c_{4}\right\}$ (right), which is smaller than the horizontal one and is represented by four points and a rotation angle $\alpha_{B}$ (refer to Table 5).

The center of box container $c_{B}\left(x_{B}, y_{B}\right)$, the centroid of convex $o_{C}\left(x_{C}, y_{C}\right)$, and the centroid of stroke $o_{S}(\bar{x}, \bar{y})$ are

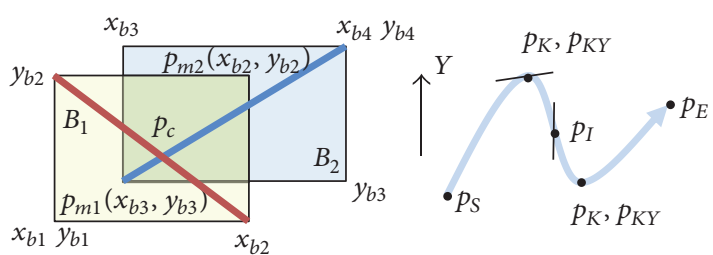

Figure 7: Minimum box and special points.

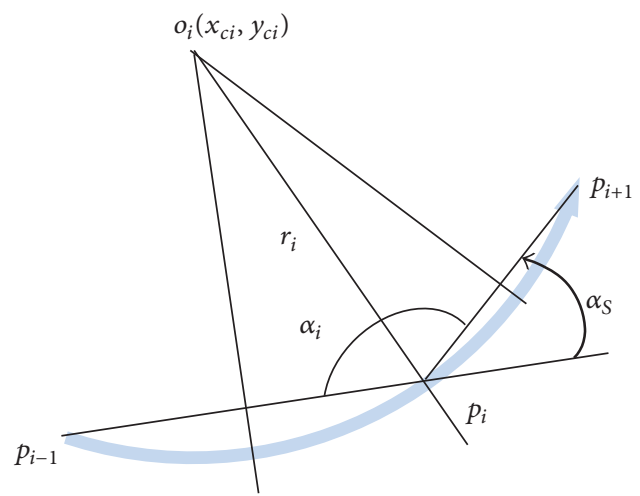

FIgURE 8: Arc center, radius, and included angle.

different (Figure 6). If two segments intersect each other, their containers must be overlapped (Figure 7), and there must exist a minimum box $B_{\min }\left(p_{m 1}, p_{m 2}\right)$ and the cross point of two segments $p_{c}\left(x_{c}, y_{c}\right)$ must be within the minimum box as well.

There are four cases in the calculation of cross point: the first segment is vertical, the second segment is vertical, two segments are collinear, and both are in general position. The knee point $p_{K}$ and the inflection point $p_{I}$ are different. The former is a sharp turning and its tangent line does not cross the stroke. The latter is a smooth turning and its tangent line crosses the stroke. The axial knee point $p_{K x}$ or $p_{K y}$ is a turning point along the $x$-axis or $y$-axis, respectively.

Two continuous and unparallel segments can be used to form an arc (Figure 8). The arc center $o_{i}\left(x_{c i}, y_{c i}\right)$ and radius $r_{i}$ are certain. $r_{i}$ can be used as the radius of curvature of the point $p_{i}$.

The convex hull of stroke $C_{S}$ is a convex polygon containing all the points of stroke [21]. There are quite many methods to find the convex hull, such as Gift-Wrapping, GrahamScan, or QuickHull method. Gift-Wrapping is simple and fast enough for the point set of a stroke; therefore, it is applied to this work. At first, the point with the minimum $y$ is the start point; secondly, the segments from the start point to the rest of the points are set up; thirdly, the angles of these segments with the $X$-axis are calculated out and then sorted; fourthly, the point with the minimum angle is added to the convex hull set; fifthly, the last three points are linked to two vector segments; if the second segment turns right, the last point in the convex hull is deleted; otherwise, it is as the current start point and then the second step is repeated until all the points are checked. 
TABle 3: Coordinate features.

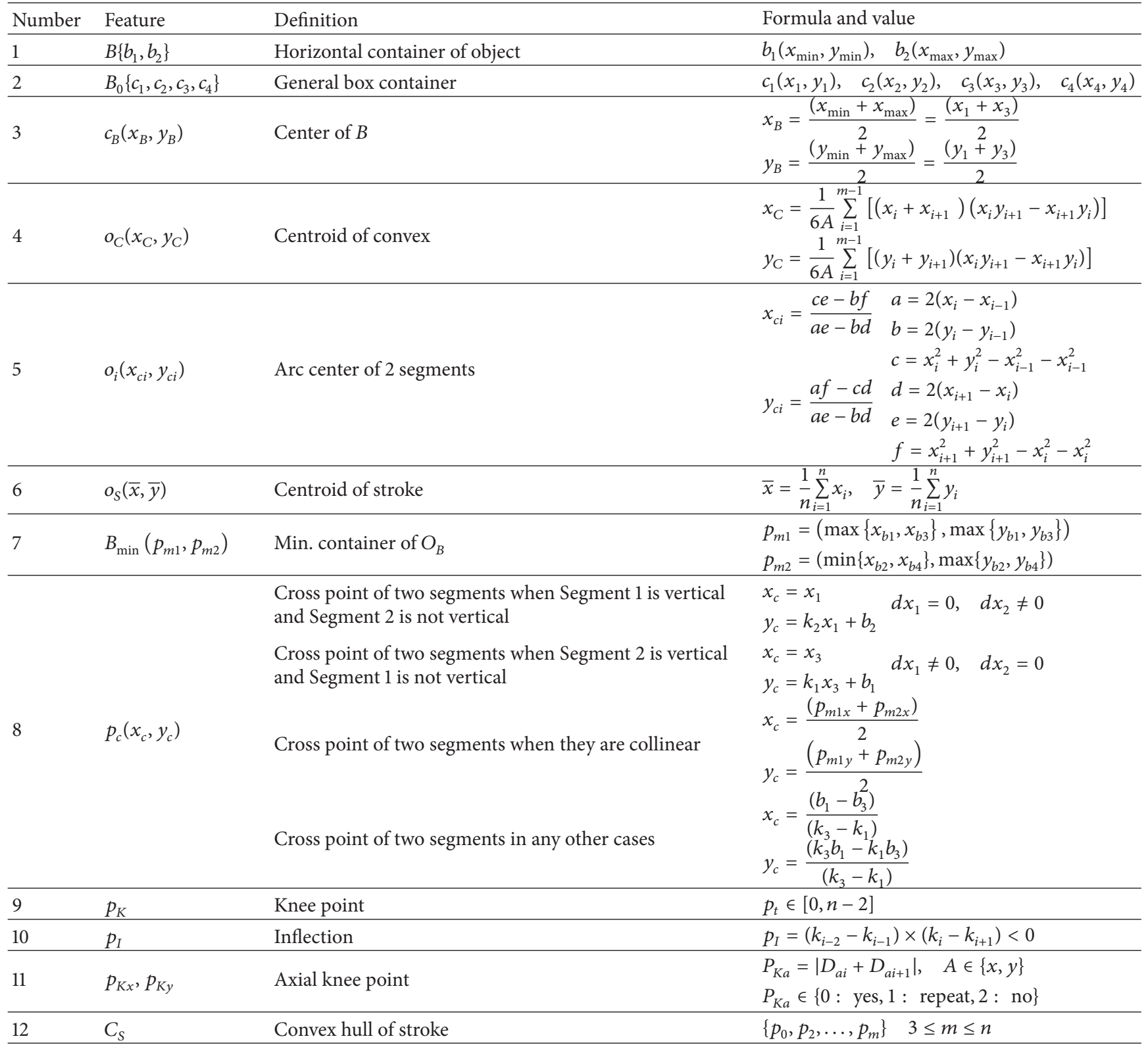

3.3. Length and Width Features. The lengths and widths are geometric features. Their positions are shown in Figure 9 and the definitions are listed in Table 4 . The length of segment $d_{i, i+1}$ and the length of stroke $L_{S}$ are very useful. The average radius of arc $\bar{r}$ stands for the curling degree of stroke and the difference of radius $\Delta r$ reflects the vibration of it. The dimensions of container $w_{B}, h_{B}$, and $p_{B}$ stand for the size of geometry. The length $L_{S E}$ between both ends of stroke is a span of stroke and the difference of two values $d a_{i}$ is also a span between two points.

3.4. Angle Features. The angles are also geometric features. Their size stands for the position relationship between two segments (Figures 8 and 9). The value of azimuth angle $\theta_{A i}$,

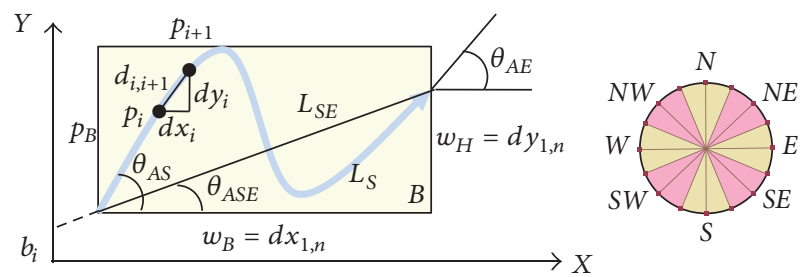

FIgURE 9: Minimum box and special points.

$\theta_{A S E}, \theta_{A S}$, or $\theta_{A E}$ is from 0 to $360^{\circ}$, which can be divided into eight zones, that is, east, west, north, south, northeast, northwest, southeast, and southwest, as shown in Table 5. 
TABLE 4: Length features.

\begin{tabular}{|c|c|c|c|}
\hline Number & Feature & Definition & Formula and value \\
\hline 1 & $d a_{i}$ & $\begin{array}{l}\text { Difference of } \\
\text { two values }\end{array}$ & $d a_{i}=a_{i+1}-a_{i} \quad a \in\{x, y, v\}$ \\
\hline 2 & $b_{i}$ & $\begin{array}{l}\text { Intercept of } \\
\text { segment }\end{array}$ & $b_{i}=y_{i}-k_{i} x_{i}$ \\
\hline 3 & $d_{i, i+1}$ & $\begin{array}{l}\text { Length of } \\
\text { segment }\end{array}$ & $d_{i, i+1}=\left|\vec{p}_{i, i+1}\right|$ \\
\hline 4 & $L_{S}$ & Length of stroke & $L_{S}=\sum_{i=1}^{n-1} d_{i, i+1}$ \\
\hline 5 & $w_{B}$ & Width of $B$ & $w_{B}=x_{\max }-x_{\min }=d_{c 1 c 2}$ \\
\hline 6 & $h_{B}$ & Height of $B$ & $h_{B}=y_{\max }-y_{\min }=d_{c 2 c 3}$ \\
\hline 7 & $p_{B}$ & Perimeter of $B$ & $p_{B}=2\left(w_{B}+h_{B}\right)$ \\
\hline 8 & $L_{S E}$ & $\begin{array}{l}\text { Length between } \\
\text { both ends }\end{array}$ & $L_{S E}=d_{1 n}$ \\
\hline 9 & $r_{i}$ & Radius of arc & $r_{i}=d_{i, c i}$ \\
\hline 10 & $\bar{r}$ & $\begin{array}{l}\text { Average radius } \\
\text { of arc }\end{array}$ & $\bar{r}=\frac{1}{(n-2) \sum_{i=1}^{n-2} r_{i}}$ \\
\hline 11 & $\Delta r$ & $\begin{array}{l}\text { Difference of } \\
\text { radius }\end{array}$ & $\Delta r=r_{\max }-r_{\min }$ \\
\hline
\end{tabular}

TABLE 5: Angle features.

\begin{tabular}{|c|c|c|c|}
\hline Number & Feature & Definition & Formula and value \\
\hline 1 & $\alpha_{B}$ & $\begin{array}{l}\text { Rotation } \\
\text { angle of } B\end{array}$ & $\alpha_{B}=\arctan \left(\frac{y_{2}-y_{1}}{x_{2}-x_{1}}\right) \in\left[0,360^{\circ}\right]$ \\
\hline 2 & $\theta_{A i}$ & $\begin{array}{l}\text { Azimuth } \\
\text { angle of } \\
\text { segment }\end{array}$ & $\begin{array}{l}\theta_{A i}=\arctan \left(\frac{y_{i+1}-y_{i}}{x_{i+1}-x_{i}}\right) \in \\
\{N, S, E, W, N E, N W, S E, S W\}\end{array}$ \\
\hline 3 & $\theta_{A S E}$ & $\begin{array}{l}\text { Azimuth } \\
\text { angle of } L_{S E}\end{array}$ & $\begin{array}{l}\theta_{A S E}=\arctan \left(\frac{y_{n}-y_{1}}{x_{n}-x_{1}}\right) \epsilon \\
\{N, S, E, W, N E, N W, S E, S W\}\end{array}$ \\
\hline 4 & $\theta_{A S}$ & $\begin{array}{l}\text { Azimuth } \\
\text { angle of } \\
\text { start }\end{array}$ & $\begin{array}{l}\theta_{A S}=\arctan \left(\frac{y_{2}-y_{1}}{x_{2}-x_{1}}\right) \in \\
\{N, S, E, W, N E, N W, S E, S W\}\end{array}$ \\
\hline 5 & $\theta_{A E}$ & $\begin{array}{l}\text { Azimuth } \\
\text { angle of end }\end{array}$ & $\begin{array}{l}\theta_{A E}=\arctan \left(\frac{y_{n}-y_{n-1}}{x_{n}-x_{n-1}}\right) \epsilon \\
\{N, S, E, W, N E, N W, S E, S W\}\end{array}$ \\
\hline 6 & $\alpha_{S}$ & $\begin{array}{l}\text { Rotation } \\
\text { angle of } \\
\text { segment }\end{array}$ & $\alpha_{S}=\vec{p}_{i-1, i} \times \vec{p}_{i, i+1} \in\{<1,0,>1\}$ \\
\hline 7 & $\alpha_{i}$ & $\begin{array}{l}\text { Included } \\
\text { angle }\end{array}$ & $\begin{array}{l}\alpha_{i}=\frac{180}{\pi} \arccos (t) \in\{0,180) \quad t= \\
\left(\frac{d_{i-1, i}^{2}+d_{i, i+1}^{2}-d_{i-1, i+1}^{2}}{2 d_{i-1, i} d_{i, i+1}}\right)\end{array}$ \\
\hline
\end{tabular}

However, the rotation angle of segment $\alpha_{S}$ is not the real value in degree; it is a direction with the values of $<1,0$, and $>1$, standing for turning left, collineation, and turning right, respectively. The azimuth angles $\theta_{A S E}, \theta_{A S}$, and $\theta_{A E}$ are useful for some special applications. $\theta_{A S E}$ is used to judge the general direction of stroke from start point to the end point. For example, the shapes of undo and redo gesture commands are quite similar; however, their $\theta_{A S E}$ angles are opposite. $\theta_{A S}$ is the azimuth angle of start point and is used to judge the start direction of stroke, and $\theta_{A E}$ is the azimuth angle of end point and is used to judge the end direction of stroke. For
TABle 6: Performance features.

\begin{tabular}{|c|c|c|c|}
\hline Number & Feature & Definition & Formula and value \\
\hline 1 & $S_{B}$ & Area of $B$ & $S_{B}=w_{B} h_{B}$ \\
\hline 2 & $S_{C}$ & Area of convex & $S_{C}=\frac{1}{2}\left|\sum_{i=1}^{m-1}\left(x_{i} y_{i+1}-x_{i+1} y_{i}\right)\right|$ \\
\hline 3 & $n_{T L}$ & $\begin{array}{l}\text { Times of } \\
\text { turning left }\end{array}$ & $n_{T L}=n_{T L}+1 \quad \alpha_{\mathrm{S}}<0$ \\
\hline 4 & $n_{T R}$ & $\begin{array}{l}\text { Times of } \\
\text { turning right }\end{array}$ & $n_{T R}=n_{T R}+1 \quad \alpha_{S}>0$ \\
\hline 5 & $n_{S}$ & $\begin{array}{l}\text { Self-intersection } \\
\text { times }\end{array}$ & $n_{S} \in[0, n-3]$ \\
\hline 6 & $n_{K}$ & $\begin{array}{l}\text { Number of knee } \\
\text { points }\end{array}$ & $n_{K} \in[0, n-2]$ \\
\hline 7 & $n_{K X}$ & $\begin{array}{l}\text { Number of } \\
x \text {-axis knee } \\
\text { points }\end{array}$ & $n_{K X} \in[0, n-2]$ \\
\hline 8 & $n_{K Y}$ & $\begin{array}{l}\text { Number of } \\
y \text {-axis knee } \\
\text { points }\end{array}$ & $n_{K Y} \in[0, n-2]$ \\
\hline 9 & $n_{I}$ & $\begin{array}{l}\text { Number of } \\
\text { inflection points }\end{array}$ & $n_{I} \in[0, n-2]$ \\
\hline 10 & $k_{i}$ & $\begin{array}{l}\text { Slope of } \\
\text { segment }\end{array}$ & $k_{i}=\frac{d y_{i}}{d x_{i}}=\operatorname{tg} \theta_{A i}$ \\
\hline 11 & $k_{B}$ & Aspect ratio of $B$ & $k_{B}=\frac{h_{B}}{w_{B}} \quad k_{B} \in\{<1,=1,>1\}$ \\
\hline 12 & $k_{T L}$ & $\begin{array}{l}\text { Ratio of turning } \\
\text { left }\end{array}$ & $\begin{array}{l}k_{T L}=\frac{n_{T L}}{n_{T L}+n_{T R}} \times 100 \% \epsilon \\
{[0,100]}\end{array}$ \\
\hline 13 & $k_{T R}$ & $\begin{array}{l}\text { Ratio of turning } \\
\text { right }\end{array}$ & $\begin{array}{l}k_{T R}=\frac{n_{T R}}{n_{T L}+n_{T R}} \times 100 \% \epsilon \\
{[0,100]}\end{array}$ \\
\hline 14 & $\delta r_{\max }$ & $\begin{array}{l}\text { Max. ratio of } r \\
\text { deviation }\end{array}$ & $\delta r_{\max }=\frac{\left(r_{\max }-\bar{r}\right)}{\bar{r}} \times 100 \%$ \\
\hline & $\delta r_{\min }$ & $\begin{array}{l}\text { Min. ratio of } r \\
\text { deviation }\end{array}$ & $\delta r_{\min }=\frac{\left(\bar{r}-r_{\min }\right)}{\bar{r}} \times 100 \%$ \\
\hline 15 & $v_{i}$ & Speed of point & $v_{i}=\frac{d_{i}}{t} \approx d_{i}$ \\
\hline 16 & $\bar{v}$ & $\begin{array}{l}\text { Average speed } \\
\text { of point }\end{array}$ & $\bar{v}=\frac{L_{S}}{(n-1)}$ \\
\hline 17 & $\Delta v$ & Size of speed & $\Delta v=v_{\max }-v_{\min }$ \\
\hline 18 & $\delta v_{\max }$ & $\begin{array}{l}\text { Max. ratio of } v \\
\text { deviation }\end{array}$ & $\delta v_{\max }=\frac{\left(v_{\max }-\bar{v}\right)}{\bar{v}} \times 100 \%$ \\
\hline 19 & $\delta v_{\min }$ & $\begin{array}{l}\text { Min. ratio of } v \\
\text { deviation }\end{array}$ & $\delta v_{\min }=\frac{\left(\bar{v}-v_{\min }\right)}{\bar{v}} \times 100 \%$ \\
\hline 20 & $a_{i}$ & $\begin{array}{l}\text { Acceleration of } \\
\text { point }\end{array}$ & $\begin{array}{l}a_{i}=\frac{v_{i}-v_{i-1}}{t} \approx v_{i}-v_{i-1} \approx \\
d_{i}-d_{i-1}\end{array}$ \\
\hline
\end{tabular}

example, the select command " $\checkmark$ " in Figure 3 is determined by these three angles. $\theta_{A S}$ should be around $S E, \theta_{A E}$ should be around $N E$, and $\theta_{A S E}$ should also be around $S E$, which will limit effectively the shape of select command to a normal one.

3.5. Performance Features. Some features standing for the inner characteristics of a stroke are defined as the performance features (Table 6).

The areas, $S_{B}$ and $S_{C}$ (Figure 6, left), represent the size of geometries [22]. The number of times of turning left $n_{T L}$ or right $n_{T R}$ stands for a kind of sketching pattern. The number 
TABLE 7: Auxiliary features.

\begin{tabular}{|c|c|c|c|}
\hline Number & Feature & Definition & Formula and value \\
\hline 1 & $\begin{array}{l}D_{x i} \\
D_{y i}\end{array}$ & Direction of change & $D_{a i}= \begin{cases}1 & d a_{i}>0 \\
0 & d a_{i}=0, \quad a \in\{x, y\} \\
-1 & d a_{i}<0\end{cases}$ \\
\hline 2 & $O_{B}$ & Overlapping of $B_{1}$ and $B_{2}$ & $O_{B}= \begin{cases}1 & x_{b 2} \geq x_{b 3}\left|x_{b 4} \geq x_{b 1}\right| y_{b 2} \geq y_{b 3} \mid y_{b 4} \geq y_{b 1} \\
0 & \text { otherwise }\end{cases}$ \\
\hline 3 & $P_{s}$ & Position of two segments & $P_{s}= \begin{cases}2 & k_{1} \neq k_{2} \\
1 & k_{1}=k_{2}, b_{1}=b_{2} \\
0 & k_{1}=k_{2}, b_{1} \neq b_{2}\end{cases}$ \\
\hline
\end{tabular}
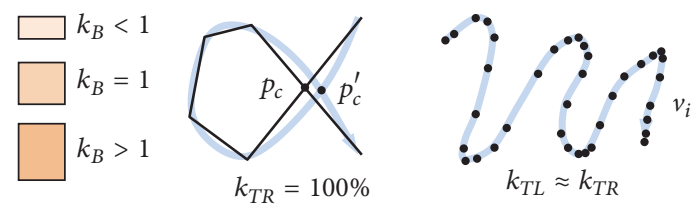

FIGURE 10: Some performance features.

of times of self-intersection $n_{S}$ represents the complexity of stroke trace; for instance, $n_{S}=1$ (Figure 10, middle); the cross point $p_{c}$ may be different from the real one $p_{c}^{\prime}$ [23]. The slope of segment $k_{i}$, similar to the azimuth angle of segment $\theta_{A i}$, gives the direction of segment. The aspect ratio of container represents the shape of the box. The values with $k_{B}<1$, $k_{B}=1$, or $k_{B}>1$ stand for the notion that the shape of the container is a flat rectangle, square, or tall rectangle, respectively (Figure 10, left). The ratios, $k_{T L}$ and $k_{T R}$, reflect the level of parameter changed; for example, the stroke of $\alpha$ sign (Figure 10, middle) is completely turning right; however, the stroke of $m$ sign may have $k_{T L} \approx k_{T R}$ (right). The speed $v_{i}$, average speed $\bar{v}$, size of speed $\Delta v$, and acceleration $a_{i}$ stand for the performance of sketching habits. In addition, the speed can be used to find the turning points, where the speed is lower than that in other sections of stroke (Figure 10, right). The ratios of deviation, $\delta r_{\max }, \delta r_{\min }, \delta v_{\max }$, and $\delta v_{\min }$, reflect the vibration of the parameters.

3.6. Auxiliary Features. Some features are used for the calculation of other features (Table 7). The change direction of segment in $Y$-axis $D_{y i}$, for example, is defined as $\{1,0,-1\}$ for the stroke going up or down, respectively (Figure 11, left). If two containers are overlapped, the value $O_{B}$ is 1 , otherwise 0 (Figure 11, middle). If two segments are intersected in a general case, the value of $P_{s}$ is 2 ; for the special case of collineation, it is 1 , otherwise 0 (Figure 11, right). These features represent the relationship of two parameters, such as the relationship of direction, overlapping, or position.

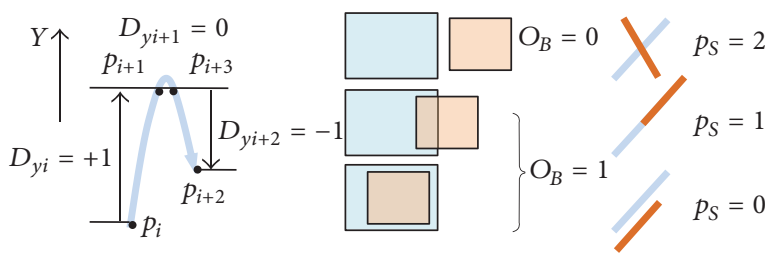

FIGURE 11: Position relationship and values.

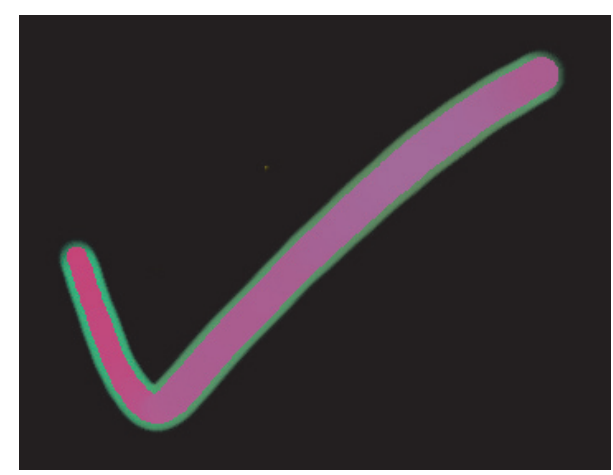

FIGURE 12: The effect of a select gesture command.

\section{Added Features}

Added features depend on the real applications to some extent. Here, only three kinds of features are discussed. Those are control features of stroke expression, calculated features, and curve features.

4.1. Control Features of Stroke Expression. Unlike the data of image, the data of stroke does not contain features such as color, grayscale, pen type, and width. The stroke can be drawn as natural as possible in AutoSketch with Chinese calligraphy art effect. Therefore, the pressure information is added to control the width and color of stroke. An example of gesture command stroke is shown in Figure 12, and the related 
TABLE 8: Stroke expression features.

\begin{tabular}{|c|c|c|c|c|}
\hline Number & Feature & Definition & $\begin{array}{l}\text { Formula and } \\
\text { value }\end{array}$ & Example \\
\hline 1 & $D$ & $\begin{array}{l}\text { Display } \\
\text { stroke }\end{array}$ & $D \in\{Y, N\}$ & $Y$ \\
\hline 2 & $D_{P}$ & Display point & $D_{P} \in\{Y, N\}$ & $Y$ \\
\hline 3 & $D_{S}$ & $\begin{array}{l}\text { Display } \\
\text { stroke }\end{array}$ & $D_{S} \in\{Y, N\}$ & $Y$ \\
\hline 4 & $P_{R}$ & $\begin{array}{l}\text { Pressure into } \\
\text { radius }\end{array}$ & $P_{R} \in\{Y, N\}$ & $Y$ \\
\hline 5 & $P_{C}$ & $\begin{array}{l}\text { Pressure into } \\
\text { color }\end{array}$ & $P_{C} \in\{Y, N\}$ & $Y$ \\
\hline 6 & $F$ & Fill with $C / G$ & $F \in\{Y, N\}$ & Y \\
\hline 7 & $S$ & $\begin{array}{l}\text { Color or } \\
\text { radius change }\end{array}$ & $S \in\{Y, N\}$ & Y \\
\hline 8 & $E$ & $\begin{array}{l}\text { Edge } \\
\text { antialiasing }\end{array}$ & $E \in\{Y, N\}$ & $Y$ \\
\hline 9 & $Z$ & $\begin{array}{l}\text { Zone of } \\
\text { affection }\end{array}$ & $Z \in\{Y, N\}$ & $Y$ \\
\hline 10 & $M$ & $\begin{array}{l}\text { Color or } \\
\text { grayscale }\end{array}$ & $M \in\{C, G\}$ & C \\
\hline 11 & $K$ & $\begin{array}{l}\text { Width or } \\
\text { radius scale }\end{array}$ & $K \in[1,100]$ & 1 \\
\hline 12 & $T$ & $\begin{array}{l}\text { Transparency } \\
\text { of stroke }\end{array}$ & $T \in[0,100]$ & 1 \\
\hline 13 & $R_{S}$ & $\begin{array}{l}\text { Start radius } \\
\text { of stroke }\end{array}$ & $R_{S} \in[1,100]$ & 6 \\
\hline 14 & $R_{E}$ & $\begin{array}{l}\text { End radius of } \\
\text { stroke }\end{array}$ & $\begin{array}{l}R_{E} \in \\
{\left[R_{S}, 100\right]}\end{array}$ & 42 \\
\hline 15 & $W_{E}$ & $\begin{array}{l}\text { Edge width of } \\
\text { stroke }\end{array}$ & $W_{E} \in[1,10]$ & 5 \\
\hline 16 & $W_{P}$ & Width of pen & $W_{p} \in[1,10]$ & 1 \\
\hline 17 & $C_{S}$ & $\begin{array}{l}\text { Start color of } \\
\text { stroke }\end{array}$ & $\begin{array}{l}C_{S} \in \\
\left\{R_{S}, G_{S}, B_{S}\right\}\end{array}$ & $243,20,87$ \\
\hline 18 & $C_{E}$ & $\begin{array}{l}\text { End color of } \\
\text { stroke }\end{array}$ & $\begin{array}{l}C_{E} \in \\
\left\{R_{E}, G_{E}, B_{E}\right\}\end{array}$ & $103,182,228$ \\
\hline
\end{tabular}

parameter values are listed in Table 8 . The first nine features (Table 8) are switch parameters with the value of 1 or 0 , which stands for yes or no attributed to the control of the display status of stroke, respectively. There are two color modes for filling, color or grayscale. The color is in $R G B$ with the values from 0 to 255 . The transparency value is from 0 to 100 . The rest of the values are in pixel.

4.2. Calculated Features. In order to express a vivid stroke and use the pressure feature in further applications, some calculated features have been proposed (Table 9).

The pressure of stroke can be converted into the radius $R_{i}$ or width $W_{P}$ of pen within the start radius $R_{S}$ and the end radius $R_{E}$; it can also be transformed into $R G B$ color or grayscale, using the value of $255-P_{s}$ or $P_{s}$. If distance between two points is quite large, the stroke may be intermittent (Figure 13(a)), and it should use much more circles to fill the gaps. $n_{c}$ is the number of circles used for filling the

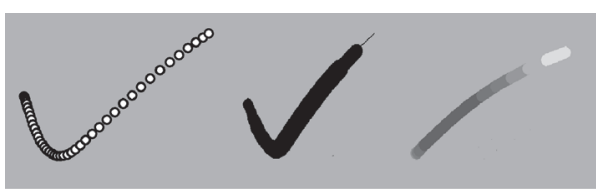

$\begin{array}{lll}\text { (a) Intermittent } & \text { (b) Sharp tail } & \text { (c) Unsmooth color }\end{array}$

FIgURE 13: Position relationship and values.

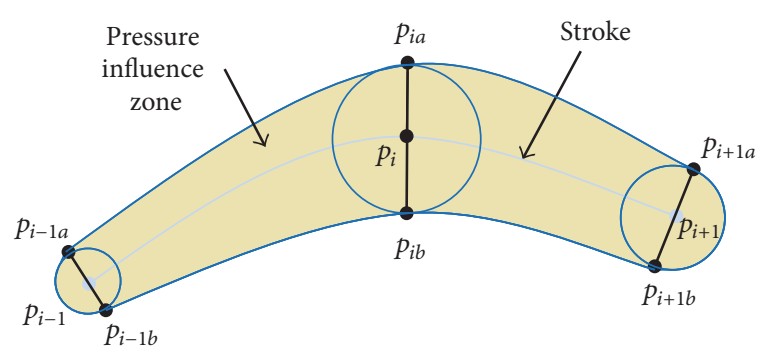

FIGURE 14: Influence zone of pressure.

gap between two points. The step $k_{s}$ is controlled by the number $n_{c}$ and density $k_{s}$ of circles. Because the pressures of two consecutive points are different, the converted radiuses must be different, and the stroke between two points may be shrunk or expanded sharply and is not smooth at the edge of the stroke (Figure 13(b)). Therefore, the radiuses between two points should be changed gradually. The transit radius $R_{j}$ is controlled by $k_{s}$. The color of stroke should be changed gradually in the same way; otherwise, the stroke will look like the one shown in Figure 13(c).

Even after doing this, the stroke still looks like a zigzag at the edge, and it cannot be smoothed like image antialiasing. Therefore, a pseudoantialiasing method is applied to smooth the edge of the stroke. The colors can be divided into four parts: the background color $G_{B}$, the stroke color $G_{S}$, the edge color $G_{E}$, and the middle color $G_{M}$. The last two can be calculated out once the stroke and background colors are known. Sometimes, the opacity value $A[0.1]$ is applied to call some functions so that the value of transparency $T[0,100]$ should be converted into the opacity value, and vice versa. Because the stroke is drawn repeatedly with circles, the transparency should also be changed gradually; the transit transparency $\Delta T$ is determined by the width of edge $W_{E}$.

The pressure of stroke can also be used to control the influence zone of pressure (Figure 14), which is an area of stroke or surface changed in the manipulation of stroke or surface modification. The coordinates $p_{i a}$ and $p_{i b}$ can be obtained according to the radius $r_{i}$, which is converted from the pressure.

4.3. Curve Features. There are quite many features coming from the relationship of parameters, such as $X-Y, X-P$, and $X-V$, which are discussed above. However, from a stroke, there are still some other relationships such as $X-\theta_{A P}$ or $X-\theta_{E P}$ (Table 10). A stroke $S$ contains a lot of points; some of them are actually the noise points which make the stroke unsmooth. Therefore, the stroke should be preprocessed and compressed with a few good points to become a smooth curve 
TABLE 9: Calculated expression features.

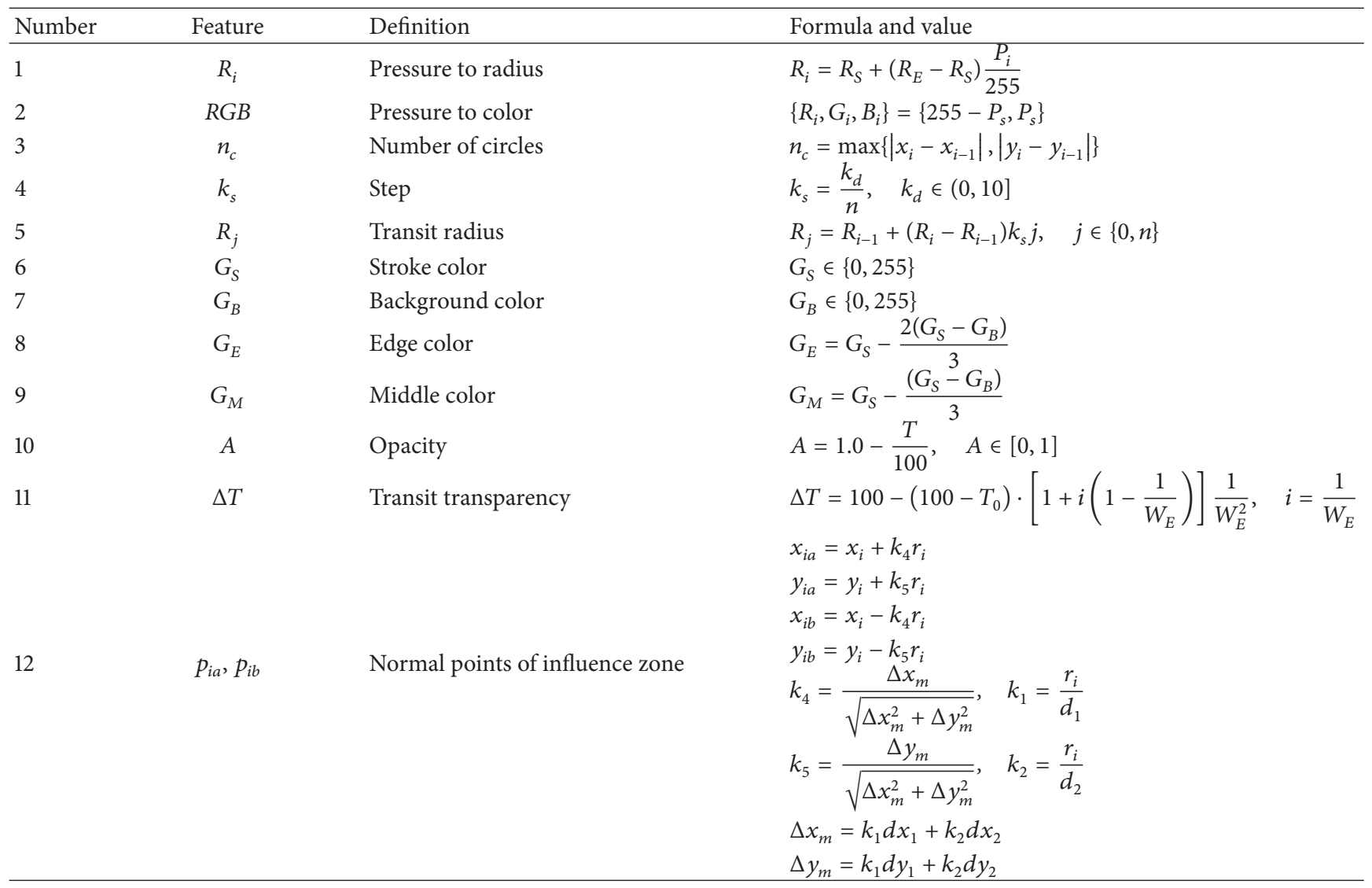

$S_{C}$ and is drawn out using a spline $S_{S}$, which is compressed further by the application of some curve fitting algorithms. In addition, the knee point curve $S_{K}$ is needed for some special applications, such as the identification of gesture commands and geometries. The original pressure curve $S_{X P}$ corresponding to the stroke cannot be applied directly. Similarly, it should also be compressed and smoothed to the curve $S_{X P C}$, which is then translated to the $X$-axis and becomes another curve $S_{X P G}$, where the start point is set to the origin $o$. It is then rotated along the origin $o$ to make both ends of the curve $S_{X P G}$ become locked on the $X$-axis and become the curve $S_{X P E}$. The curve $S_{X P E}$ may be fit into a parabola curve $S_{X P P}$ for controlling the stroke changing in one direction $(z$ direction in parametric space), which can control easily the shape of spatial curve. The pressure curve $X-P$ can be mixed with the stroke in $X-Y$ to form a spatial curve $S_{X Y Z}$ consequently while the pressure is converted into $Z$ to some extent (Figure 15).

Currently, the curves $S_{X A}$ and $S_{X E}$ have not been used yet in AutoSketch. However, they give the new dimensions in the parametric space like the curve $S_{X P}$ and will be applied in further researches.

\section{Validation of Features}

All the features have been applied in AutoSketch for the identification of gesture commands listed in Figure 3, the

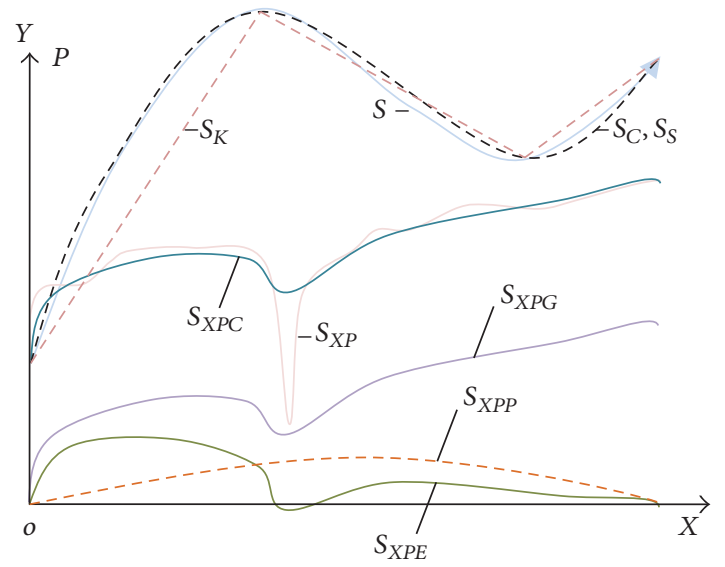

FIGURE 15: Some strokes and pressure curves.

expression of the art strokes, and the generation of spatial curve by the pressure of stroke directly.

5.1. Identification of Gesture Commands. The features in Tables 1 7 have been used to determine the commands listed in Figure 3 according to the combinations of the special conditions, as shown in Table 11. The trials demonstrate that 
TABLE 10: Curve features.

\begin{tabular}{|c|c|c|c|}
\hline Number & Feature & Definition & Formula and value \\
\hline 1 & $S$ & $\begin{array}{l}\text { Original stroke in } \\
X-Y\end{array}$ & $S=f(x, y)$ \\
\hline 2 & $S_{C}$ & $\begin{array}{l}\text { Compressed curve } \\
\text { in } X-Y\end{array}$ & $S_{C}=f\left(x^{\prime}, y^{\prime}\right)$ \\
\hline 3 & $S_{K}$ & $\begin{array}{l}\text { Knee point curve in } \\
X-Y\end{array}$ & $S_{K}=f\left(x_{K}, y_{K}\right)$ \\
\hline 4 & $S_{S}$ & Spline curve in $X-Y$ & $S_{S}=f\left(x^{\prime}, y^{\prime}\right)$ \\
\hline 5 & $S_{V}$ & Speed curve in $X-V$ & $S_{V}=f(x, v)$ \\
\hline 6 & $S_{a}$ & $\begin{array}{l}\text { Acceleration curve } \\
\text { in } X-a\end{array}$ & $S_{a}=f(x, a)$ \\
\hline 7 & $S_{X P}$ & $\begin{array}{l}\text { Pressure curve in } \\
X-P\end{array}$ & $S_{X P}=f(x, P)$ \\
\hline 8 & $S_{X P C}$ & $\begin{array}{l}\text { Compressed } \\
\text { pressure curve }\end{array}$ & $S_{X P C}=f\left(x_{C}, P_{C}\right)$ \\
\hline 9 & $S_{X P G}$ & $\begin{array}{l}\text { Generalized } \\
\text { pressure curve }\end{array}$ & $S_{X P G}=f\left(x_{C}, P_{G}\right)$ \\
\hline 10 & $S_{X P E}$ & $\begin{array}{l}\text { End-locked pressure } \\
\text { curve }\end{array}$ & $S_{X P E}=f\left(x_{C}, P_{E}\right)$ \\
\hline 11 & $S_{X P A}$ & $\begin{array}{l}\text { Arc-fitting pressure } \\
\text { curve }\end{array}$ & $S_{X P A}=f\left(x_{C}, P_{A}\right)$ \\
\hline 12 & $S_{X P P}$ & $\begin{array}{l}\text { Parabola-fitting } \\
\text { pressure curve }\end{array}$ & $S_{X P P}=f\left(x_{C}, P_{P}\right)$ \\
\hline 13 & $S_{X P Z}$ & Pressure-to- $Z$ curve & $S_{X P Z}=f\left(x_{C}, z_{C}\right)$ \\
\hline 14 & $S_{X Y Z}$ & Spatial curve & $S_{X Y Z}=f\left(x_{C}, y_{C}, z_{C}\right)$ \\
\hline 15 & $S_{X A}$ & $\begin{array}{l}\text { Original stroke in } \\
X-\theta_{A P}\end{array}$ & $S_{X A}=f\left(x, \theta_{A P}\right)$ \\
\hline 16 & $S_{X E}$ & $\begin{array}{l}\text { Original stroke in } \\
X-\theta_{E P}\end{array}$ & $S_{X E}=f\left(x, \theta_{E P}\right)$ \\
\hline
\end{tabular}

TABLE 11: Some identifying conditions.

\begin{tabular}{lll}
\hline Number & Comds. & Identifying conditions \\
\hline 1 & Select & $\left(n_{S}=1, n_{K}=0\right),\left(\theta_{\mathrm{AS}}=S E \mid S\right)$, \\
& & $\left(\theta_{A E}=N E \mid N\right), k_{S K E}=\frac{L_{K E}-L_{S K}}{L_{K E}+L_{S K}}>-0.2$ \\
& & $\left(n_{S}=1, n_{K} \geq 2\right)$, \\
2 & Undo & $\left(\theta_{A S E}>157.5^{\circ} \mid \theta_{A S E}<-90^{\circ}\right)$ \\
3 & Redo & $\left(n_{S}=1, n_{K} \geq 2\right),\left(-22.5^{\circ}<\theta_{A S E}<90^{\circ}\right)$ \\
4 & Delete & $\left(n_{S}=0, n_{K}>3\right),\left(\alpha_{1} \geq 15^{\circ} \mid \alpha_{n_{K}} \geq 15^{\circ}\right)$ \\
5 & Smooth & $n=2 \mid\left(n_{K}=2, n=4, N_{S} \neq 1\right)$ \\
6 & Break & $n_{K}=2, n_{S}=1,\left(-157.5^{\circ}<\theta_{A S E}<-22.5^{\circ}\right)$ \\
\hline
\end{tabular}

the identification of gesture commands is quite satisfied as shown in Table 12.

5.2. Expression of Pressure Stroke. The features in Tables 8 9 have been used to express a pressure vector stroke. For real-time application, the method using the above features is called the pseudoantialiasing method in order to differentiate it from the antialiasing method of raster image in image processing. The style of stroke can be set in the attributes settings window, as shown in Figure 16. There are five different

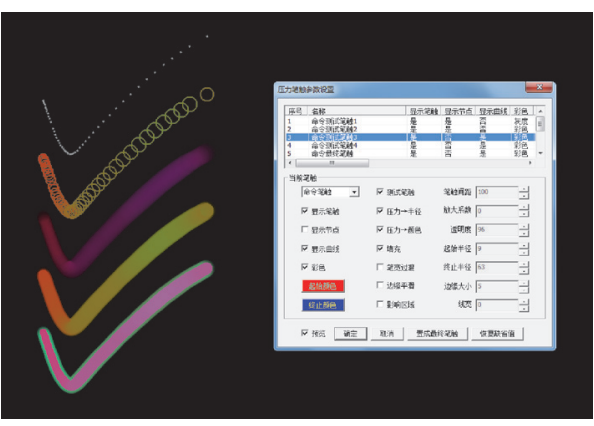

Figure 16: Test results of a gesture stroke.

TABLE 12: Evaluation of gesture commands sketched.

\begin{tabular}{lcccccccccc}
\hline \multirow{2}{*}{ Cmd. } & \multicolumn{4}{c}{ User score } & \multicolumn{3}{c}{ Err. } & \multirow{2}{*}{ Min. } & Max. & Aver. \\
& 1 & 2 & 3 & 4 & 5 & Rate & & & & \\
\hline Select & 94 & 93 & 98 & 95 & 94 & 1.85 & 4.43 & 3 & 8 & 94.8 \\
Undo & 96 & 95 & 97 & 94 & 96 & 1.75 & 3.69 & 4 & 97 & 95.6 \\
Redo & 94 & 95 & 98 & 96 & 95 & 1.75 & 3.80 & 94 & 98 & 95.6 \\
Delete & 95 & 98 & 96 & 95 & 98 & 1.95 & 4.52 & 95 & 98 & 96.4 \\
Smooth & 96 & 90 & 98 & 96 & 98 & 2.37 & 5.22 & 90 & 98 & 95.6 \\
Break & 97 & 97 & 98 & 96 & 89 & 1.80 & 5.37 & 89 & 98 & 95.4 \\
\hline
\end{tabular}

TABLE 13: Attributes and values of stroke.

\begin{tabular}{lccccc}
\hline Type & \multicolumn{5}{c}{ Value } \\
\hline Number & 1 & 2 & 3 & 4 & 5 \\
Stroke & $T 1$ & $T 2$ & $T 3$ & $T 4$ & Final \\
$D$ & $Y$ & $Y$ & $Y$ & $Y$ & $Y$ \\
$D_{P}$ & $Y$ & $Y$ & $N$ & $N$ & $N$ \\
$D_{S}$ & $N$ & $N$ & $Y$ & $Y$ & $Y$ \\
$P_{R}$ & $Y$ & $Y$ & $Y$ & $Y$ & $Y$ \\
$P_{C}$ & $Y$ & $Y$ & $Y$ & $Y$ & $Y$ \\
$F$ & $N$ & $N$ & $Y$ & $Y$ & $Y$ \\
$S$ & $N$ & $N$ & $N$ & $Y$ & $Y$ \\
$E$ & $N$ & $N$ & $N$ & $Y$ & $Y$ \\
$Z$ & $N$ & $N$ & $N$ & $N$ & $Y$ \\
$M$ & $G$ & $C$ & $C$ & $C$ & $C$ \\
$K$ & 1 & 1 & 1 & 1 & 1 \\
$T$ & 1 & 1 & 96 & 1 & 1 \\
$R_{S}$ & 2 & 8 & 9 & 6 & 6 \\
$R_{E}$ & 2 & 42 & 63 & 42 & 42 \\
$W_{E}$ & 5 & 5 & 5 & 5 & 5 \\
$W_{P}$ & 1 & 1 & 1 & 1 & 1 \\
$C_{S}$ & $232,242,21$ & $255,0,0$ & $255,0,0$ & $255,0,0$ & $243,20,87$ \\
$C_{E}$ & $91,98,225$ & $0,255,0$ & $0,0,255$ & $0,255,0$ & $103,182,228$ \\
\hline & & & & &
\end{tabular}

styles shown in the same time to check which one is better. The types of attributes and the values are listed in Table 13.

5.3. Generation of Spatial Curve. The features in Table 10 have been used to generate a spatial curve directly by the pressure of stroke. For instance, a pressure stroke is drawn in $X Z$ plane, 


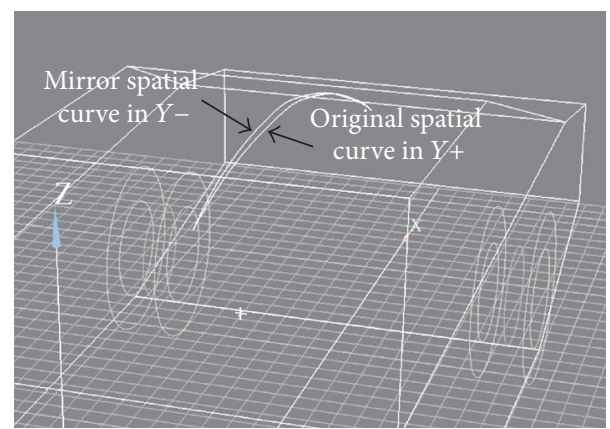

FIgURE 17: Draw directly a spatial curve.

and a spatial curve $S_{X P Z}$ is created immediately by choosing the direction in $Y+$, as shown in Figure 17. The mirror stroke is shown to demonstrate that the curve is a spatial one, not a planar one.

\section{Conclusions}

The features coming from a single vector pressure stroke have been investigated and discussed in detail. Those features are classified into three parts: the input features, the calculable features, and the added features. The input features are derived from the output of a digital pen, which may be different for the different input systems. The calculable features, to be honest, are the part of features that a stroke contains. They are just the simple and easy-to-calculate ones for the realtime application in 3D freehand sketching system. For the added features, they may be different depending on the real application, and they are added here for the expression of a vivid stroke, which is a novel pseudoantialiasing method, and the generation of a spatial stroke according to the pressure of the digital pen, which is a novel method to create a spatial curve directly on the planar digital screen. For the further researches, the azimuth and elevation angles of the digital pen may be applied in order to investigate the sketching habit and the gestures of holding the pen.

\section{Competing Interests}

The authors declare no competing interests regarding the publication of this paper.

\section{Acknowledgments}

This work is supported by the Science and Technology Plan Projects of Zhejiang Province under Grant no. 2013C31085.

\section{References}

[1] T. Igarashi, S. Matsuoka, and H. Tanaka, "Teddy: a sketching interface for 3D freeform design," in Proceedings of the 26th Annual Conference on Computer Graphics and Interactive Techniques (SIGGRAPH '99), pp. 409-416, ACM, Los Angeles, Calif, USA, 1999.
[2] S.-H. Bae, R. Balakrishnan, and K. Singh, I Love Sketch: As Natural as Possible Sketching System for Creating 3D Curve Models, UIST, 2008.

[3] Q. Li, Y. Tang, and Y. Gong, "3D sketching in AutoSketch," in Proceedings of the International Conference on Electronic \& Mechanical Engineering and Information Technology (EMEIT '11), pp. 433-436, Harbin, China, August 2011.

[4] Q. Li, L. Yang, D. Wang, and M. Gao, "The multi-stroke combination in the automotive styling from 2-D to 3-D," in Proceedings of the IEEE 11th International Conference on ComputerAided Industrial Design \& Conceptual Design (CAIDCD '10), pp. 1401-1405, IEEE, Yiwu, China, November 2010.

[5] Q. Li, L. Yang, and D. Wang, "The combination of two consecutive strokes in automotive styling from 2-D to 3D," in Proceedings of the IEEE 11th International Conference on Computer-Aided Industrial Design \& Conceptual Design (CAID\&CD '10), pp. 1526-1531, Yiwu, China, November 2010.

[6] Q. Li, N. Qi, and Y. Gong, "An algorithm of multi-stroke combination in the automotive styling," in Proceedings of the International Conference on Electronic and Mechanical Engineering and Information Technology (EMEIT '11), pp. 417-420, Harbin, China, August 2011.

[7] C. Xuan, Y. Gong, and Q. Li, "Research progress of 3D style design based on sketching," in Proceedings of the $3 \mathrm{rd}$ International Conference on Applied Mechanics, Materials and Manufacturing (ICAMMM '13), vol. 423-426, pp. 1819-1822, Dalian, China, August 2013.

[8] C. Xuan, Y. Gong, Q. Li, and N. Qi, "Study on three-dimensional freehand stroke creation," Advances in Mechanical Engineering, vol. 7, no. 5, pp. 1-13, 2015.

[9] Y. Gong, C. Xuan, J. Lou, and Q. Li, “3D automotive sketching system based on pressure-sensitivity of digital pen," Transactions of Chinese Society for Agricultural Machinery, vol. 46, no. 8, pp. 314-318, 2015.

[10] H. Li, Y. Ning, and C. Guo, "Analysis and research of regular geometry graphics recognition," Journal of Changshu Institute of Technology (Natural Sciences), vol. 21, no. 4, pp. 111-114, 2007.

[11] Q. Li, Y. Tang, and Y. Gong, "Geometry standardization of arbitrary multi-stroke sketching," in Proceedings of the International Conference on Electronic and Mechanical Engineering and Information Technology (EMEIT '11), pp. 425-428, Harbin, China, August 2011.

[12] H. Ji and H. Tian, "Sketch recognition method of combined graphics for conceptual design," Computer Science, vol. 43, no. 6, pp. 134-138, 2016.

[13] D. Liu, L. Chen, and X. Li, "Geometric structure analysis method based on scalable vector graphics," Journal of Computer Applications, vol. 36, no. 4, pp. 1163-1172, 2016.

[14] S. Wang, S. Wang, G. Wang, and M. Gao, "Segmentation of online freehand stroke using geometrical feature," Journal of Computer-Aided Design \& Computer Graphics, vol. 27, no. 9, pp. 1686-1693, 2015.

[15] S. Wang, Q. Zhang, S. Wang, G. Wang, and M. Gao, "Segmentation of online sketching using velocity features," Journal of Northwestern Polytechnical University, vol. 34, no. 2, pp. 235240, 2016.

[16] H. Feng, Z. Li, and G. Dai, "Gesture-based handwriting mathematics editing system," Computer Engineering and Applications, vol. 39, no. 5, pp. 97-99, 2003.

[17] B. Song, Research on Computer Supported Intelligent Sketching Technology for Product Conceptual Design, Northwestern Polytechnical University, Xian, China, 2003. 
[18] Q. Chen, D. Shi, G. Feng, X. Zhao, and B. Luo, "On-line handwritten flowchart recognition based on grammar description language," Computer Science, vol. 42, no. 11, pp. 113-117, 2015.

[19] M. Masry, D. Kang, and H. Lipson, "Reconstruction of a 3D object from a main axis system," in Proceedings of the AAAI Fall Symposium on Making Pen-Based Sketching Intelligent and Natural, Washington, DC, USA, 2004.

[20] M. Masry, D. Kang, I. Susilo, and H. Lipson, "A freehand sketching interface for progressive construction and analysis of 3D objects," Computers \& Graphics, vol. 29, pp. 563-575, 2005.

[21] G. Fan, W. Qu, and B. Yang, "A property of the convex hull of planar point set," Geography and Geo-Information Science, vol. 24, no. 1, pp. 46-48, 2008.

[22] J. Guo, H. Chu, and B. Lu, "Research on the algorithm for generating minimum-volume encasing box for polyhedron," Computer Applications, vol. 21, no. 1, pp. 38-41, 2001.

[23] L. B. Kara, C. M. D’Eramo, and K. Shimada, “Pen-based styling design of 3D geometry using concept sketches and template models," in Proceedings of the ACM Solid and Physical Modeling Conference, pp. 149-160, ACM Press, 2006. 


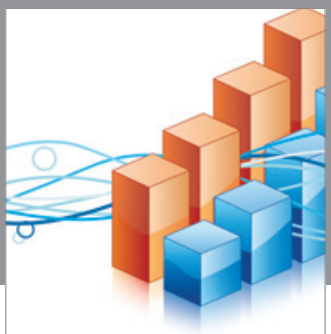

Advances in

Operations Research

vatem alat4

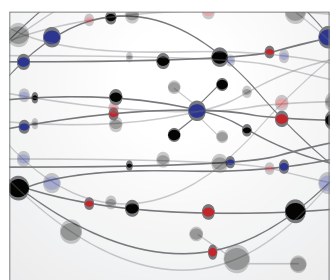

\section{The Scientific} World Journal
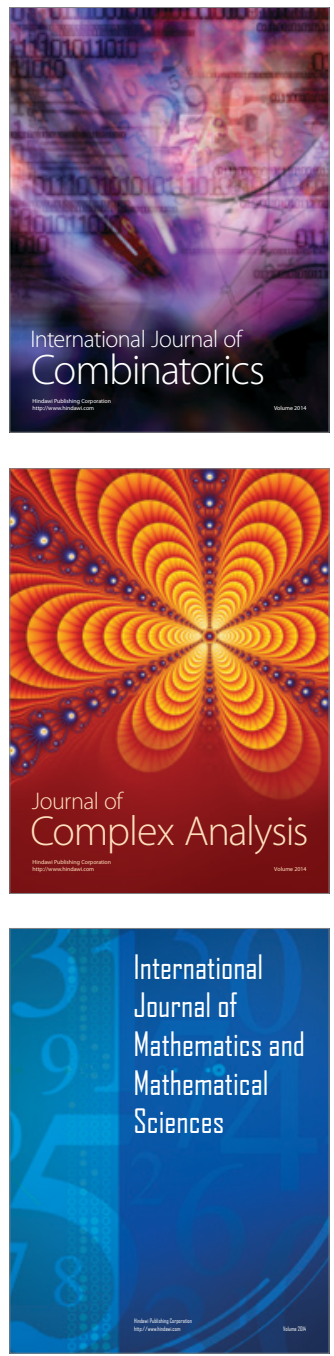
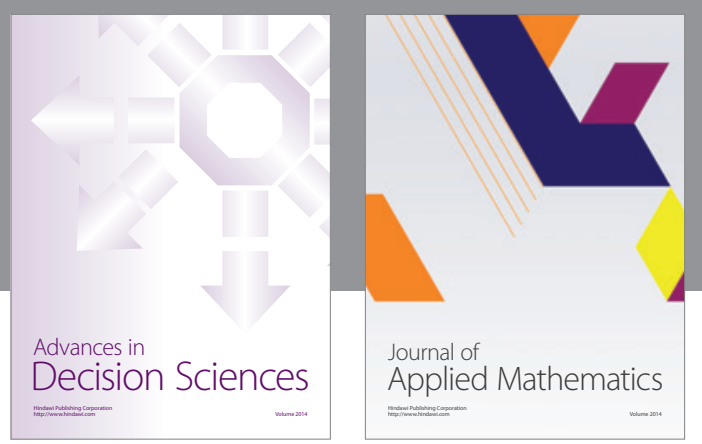

Algebra

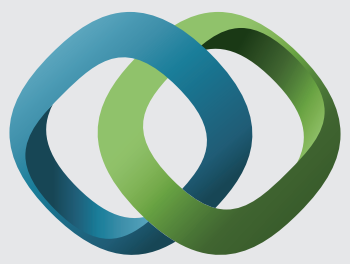

\section{Hindawi}

Submit your manuscripts at

https://www.hindawi.com
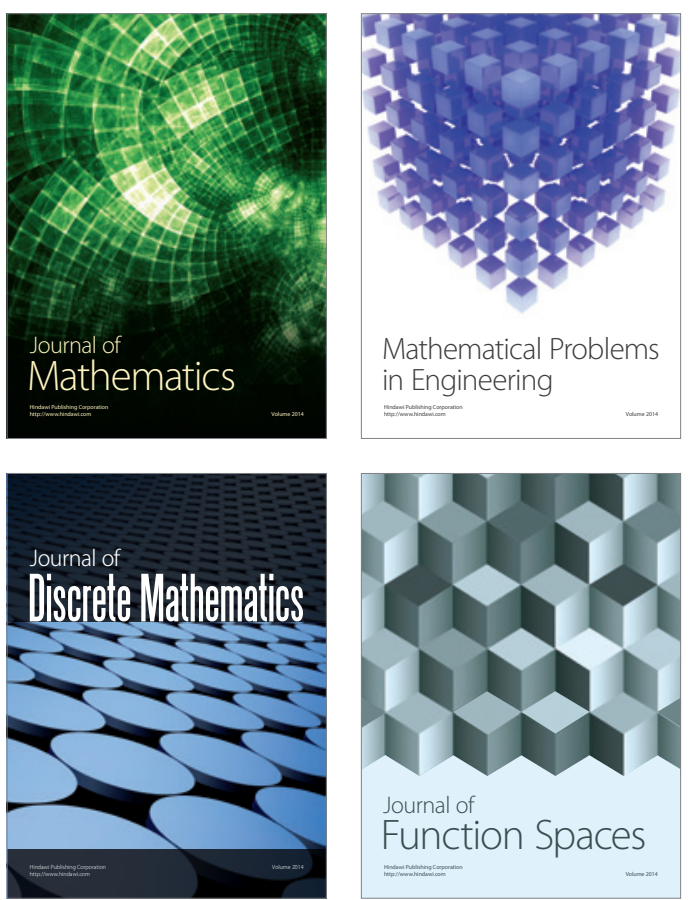

Mathematical Problems in Engineering
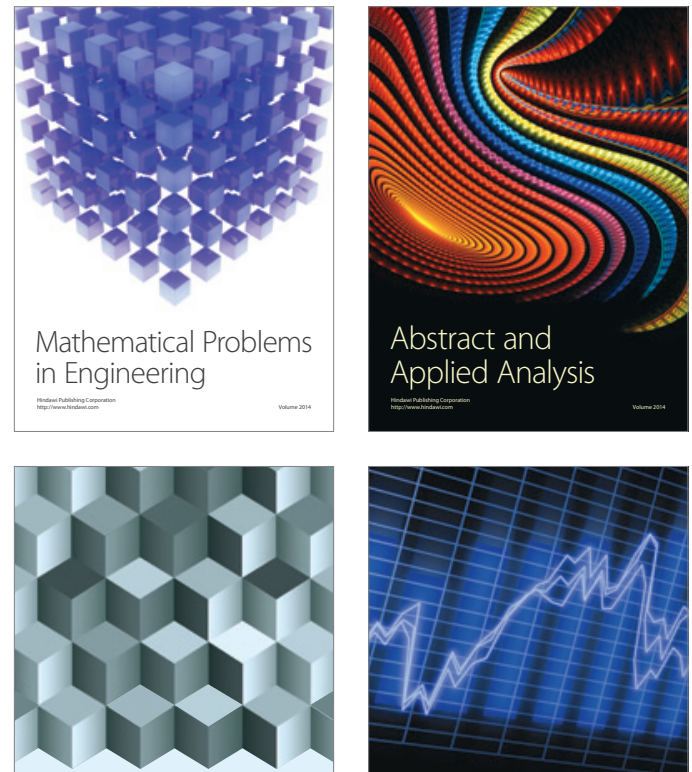

Journal of

Function Spaces

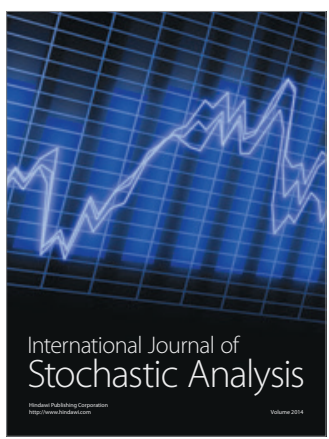

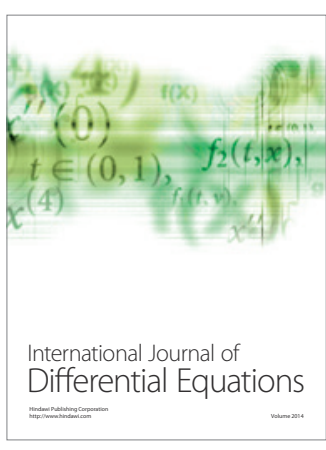
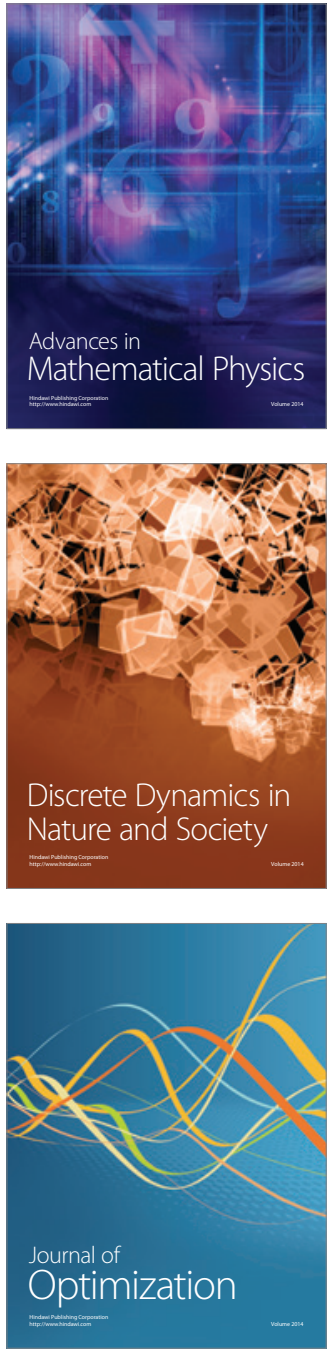